DOI: $10.17805 / z p u .2016 .3 .13$

\title{
Тезаурусные сферы: новые подходы
}

\author{
A. Н. СВАЛОВ \\ (РОССИЙСКАЯ АКАДЕМИЯ СОЦИАЛЬНЫХ НАУК, Г. МОСКВА)
}

В последние годы наблюдается повышенный интерес к знаниевой тезаурусной теории, которую разрабатывают в отечественной науке, в частности, Вал. А. Луков, Вл. А. Луков и др. Научные работы по тезаурусной тематике, выполняемые гуманитариями разных специальностей, помогают пониманию проявлений человеческой субъектности и субъективности, особенностей формирования человеком своих ценностных ориентаций, влияющих на жизненный уклад и практическую деятельность. При этом уточняются ранее высказанные положения, генерируются новые идеи. Так, одной из значимых новаций стало выдвижение концепции о тезаурусной сфере. В статье рассматриваются некоторые концептуальные положения о виртуальном образе тезаурусной сферы.

Автор предлагает воспринимать и анализировать такую сферу вне структуры тезауруса, как специализированное образование вокруг исходного субъекта. Вместе с тем образ сферы не имеет смысла вне контекста взаимодействия разных социальных субъектов, что позволяет оценивать тезаурусную сферу как интерсубъектный знаниевый феномен.

В сфере, по мнению автора, наблюдается равенство со-существования, со-бытия всех ее содержательных компонентов, что, однако, не означает их равноценности. Характерная особенность тезаурусной сферы как раз состоит в разной ценности ее компонентов для тех или иных субъектов.

Обосновывается положение о том, что изменения в содержании и структуре сферы выступают важнейшим условием ее бытования.

Ключевые слова: социальный субъект; виртуальный образ; тезаурусный подход; тезаурус; тезаурусная сфера; методология гуманитарных наук

\section{ВВЕАЕНИЕ} $\mathbf{B}_{\text {теории (см. о ней обобщающую монографию: } А \text { пов В., } \text { пуков Вл., 2013). Науч- }}$ ные работы по тезаурусной тематике, выполняемые гуманитариями разных специальностей, помогают пониманию проявлений человеческой субъектности и субъективности, особенностей формирования человеком своих ценностных ориентаций, влияющих на жизненный уклад и практическую деятельность.

При этом важно, что уточняются ранее высказанные положения, генерируются новые идеи. Так, одной из значимых новаций стало выдвижение концепции о тезаурусной сфере. В обобщенном виде она изложена в статье Вл. А. Аукова (Иуков Вл., 2014), первого руководителя научной школы по проблематике тезаурусного анализа мировой культуры. Тезаурусную сферу предложено рассматривать как специализированное образование в шарообразной модели тезауруса; высказано мнение об условной равноценности в рамках сферы различных содержательных компонентов; показано, что тезаурусная сфера подвержена изменениям, обусловленным накоплением знаний, историческим и социально-культурным развитием.

Напомним, что образ тезаурусной сферы наиболее активно использовался в публикациях по шекспировской тематике (Захаров, Ауков В., Ауков Вл., 2012: Электронный ресурс; Ауков и др., 2012: Электронный ресурс; Ауков В., Ауков Вл., 
2014; Ауков, 2015). Виртуальной шекспиросфере (Shakespeare-sphere) был посвящен научно-исследовательский проект, поддержанный грантом РГНФ в 2014 г. (см.: Аисович, Макаров, 2014).

Отмеченное, разумеется, не исключает, что конкретные идеи и построения в данном случае речь идет о тезаурусной сфере - могут стать предметом инвариантного понимания. Постараемся представить в сжатом виде некоторые размышления концептуального характера.

\section{О СФЕРЕ И ЕЕ РАСПОАОЖЕНИИ}

Прежде всего, вызывает возражение начальный тезис о том, что образ тезаурусной сферы следует рассматривать как слой в шарообразной модели тезауруса, в рамках его структуры.

По нашему мнению, образ сферы не имеет смысла вне контекста восприятия (оно отнюдь не всегда дополняется пониманием) и последующего влияния, воздействия социального субъекта, его картины мира на иные социальные субъекты и, с другой стороны, вне ответных интерпретаций и репрезентаций в разных формах и проявлениях исходного субъекта с его тезаурусом. При этом тезаурусная сфера пополняется фиксированными содержательными компонентами - реальными и виртуальными, творчески созданными и случайными, разными по тематике, характеру и особенностям исполнения. Но, подчеркнем, тезаурусная сфера никогда не замыкается на исходном социальном субъекте, хотя она и порождена, вызвана им. Сфера не может существовать, развиваться, быть жизненной без вовлечения и взаимодействия нескольких субъектов с их тезаурусами, а потому ее можно характеризовать как виртуальный интерсубъектный знаниевый феномен. Зачем же тогда представлять такое образование, в котором отражаются субъектно-субъектные и субъектно-объектные отношения, слоем внутри модели исходного тезауруса?

Нельзя не отметить еще одно обстоятельство. Предлагаемое расположение сферы как некоего слоя внутри тезауруса ведет к нестыковкам, неоправданным противоречиям в осмыслении возможной наполняемости (1) тезауруса и (2) тезаурусной сферы. Неужели богатейшая шекспиросфера, активно пополняемая и в наше время, в том числе за счет развития современных технологий и «шекспировской индустрии», входит структурным слоем в тезаурус - знаниевый ориентационный конструкт самого великого драматурга? Представляется, что рассмотрение сферы как виртуального образа вокруг социального субъекта позволяет избегать своеобразной фрактальной «матрешки», более обосновано соотносить и разграничивать содержательную наполняемость тезауруса субъекта и тезаурусной сферы. Это разные по своей наполняемости образования. Но важно, конечно, не забывать, что те или иные компоненты исходного тезауруса, особенно располагающиеся в его ядре, входят в тезаурусную сферу; без них само существование сферы не представляется возможным (например, личность Шекспира и его творческое наследие определяют стержень шекспиросферы). Исходный социальный субъект всегда выступает первым актором формирования и развития тезаурусной сферы, придает ей определенность и устойчивость.

$\mathrm{Aa}$, шекспиросфера или, скажем, пушкиносфера неотделимы от соответствующих социальных субъектов с их персональными тезаурусами. Но это никак не ве- 
дет к непременному рассмотрению названных констант в качестве внутренних образов в моделях тезаурусов, хотя понятно, что образ тезаурусной сферы вторичен по отношению к образу тезауруса. Вместе с тем, и это важно отметить, сфера способствует, как правило, поддержанию востребованности исходного тезауруса, его отдельных тезаурусных конструкций. С другой стороны, тезаурус, особенно когда он богат по своему ценностно-ориентирующему содержанию, создает благоприятные предпосылки для развития сферы.

Не следует ли тогда полагать, что тезаурусная сфера образуется вокруг исходного тезауруса? Предпочтительнее, на наш взгляд, предположить, что она образуется вокруг социального субъекта с его тезаурусом. Аело в том, что процессы пополнения и развития сферы обусловлены не только знаниевыми тезаурусами при всей их важности, но и другими причинами и обстоятельствами, которые вызывают интерес к субъекту. К примеру, характерологические особенности конкретного индивида (см. дополнительно: Канарш, 2015) могут определять интерес к нему как таковому и впоследствии сказываться на интерпретациях и репрезентациях в тезаурусной сфере.

Итак, более оправданно представлять тезаурусную сферу как поверхность, в той или иной мере объемную, с разнородными слоями, различными содержательными, смысловыми компонентами, образующуюся вокруг социального субъекта. При такой экспликации точнее было бы говорить, к примеру, о тезаурусной сфере не Шекспира, а вокруг Шекспира, хотя, конечно же, вполне допустимо использовать неологизм «шекспиросфера». Точно так же можно говорить о тезаурусной сфере вокруг общностей, будь то семья, кружок по интересам, иная малая группа или более многочисленное и сложное социальное образование. В свете отмеченного мы предпочитаем не использовать встречающееся в исследованиях выражение «сфера тезауруса», а рассматриваем именно тезаурусную сферу, уточняя тем смысловую нагрузку.

Кстати, когда речь идет об индивиде как социальном субъекте, вряд ли следует усложнять образное представление, полагая, что могут возникать несколько порожденных им тезаурусных сфер. Без множественного числа, очевидно, можно обойтись, во-первых, выделяя те или иные сегменты и слои в конкретной тезаурусной сфере, во-вторых, непременно рассматривая сферу в развитии, в определенных пространственно-временных социокультурных параметрах. Однако применительно к группам, иным социальным образованиям допустимо предположить, что вокруг них возникают несколько тезаурусных сфер, условно говоря, заглавная, основная и другие (сферы в сфере), число и характеристики которых непосредственно зависят от того, какой тип субъекта рассматривается. Но, повторим, в любом случае тезаурусная сфера порождается исходным социальным субъектом, пополняется, развивается вокруг него, но это не противоречит тому, что она выступает, как уже отмечено, интерсубъектным виртуальным феноменом.

\section{О СОДЕРЖАТЕАЬНЫХ АСПЕКТАХ \\ И РАЗВИТИИ СФЕРЫ}

В любой тезаурусной сфере представлены определенная полнота информации, различные содержательные компоненты. Заметим, что такая сфера, как интерсубъектный феномен, более открыта «входящей» информации, чем сам тезаурус, 
проявляющий в необходимых случаях функцию защиты от излишней, ненужной информации (см.: Гуманитарное знание ..., 2006: 563-564).

Вектор развития тезаурусной сферы направлен в сторону прирастания информации, воплощенной в знание. Вернемся к шекспиросфере (в качестве примера, конечно). К ней предлагается отнести обширнейший объем информации: сведения о Шекспире как реальном лице, писателе и актере; о его современниках; «материальные следы», связанные с его жизнью; интерпретации его произведений в научной и художественной формах; шекспировские «вечные образы»; библиографию изданий, переводы его произведений, исследования о нем и его творчестве; сведения о центрах изучения Шекспира, шекспировских конференциях, фестивалях, других мероприятиях; публикации в средствах массовой информации, в современных электронных ресурсах, посвященных шекспировской теме или ее затрагивающих. К шекспиросфере относят и мифы, скептические, негативные отзывы о Шекспире и его творчестве, нелепые или скандальные интерпретации. Такая концептосфера наполнена и сведениями о разнообразных проявлениях «шекспировской индустрии», в феномене которой находит выражение культ великого драматурга (Иуков Вл., 2014: 312-313; см. также: Ауков и др., 2012: Электронный ресурс).

Шекспиросфера предстает как «множественное произведение» - продукт творчества и коммуникации различных субъектов. Она уникальна по своей историчности, по структуре и богатому значимому содержанию. Но принципиально важно, чтобы отдельные сообщения и продукты, пусть даже самые интересные, относились к сфере, вписывались исследователями в ее пространство - не зря же она тезаурусная - обоснованно, «по праву». Елизаветинская эпоха, те же современники Великого Барда или, скажем, шекспировские «материальные следы» важны в данном случае не сами по себе, а с позиций шекспиросферы как интерсубъектного образа, и их необходимо рассматривать в контексте тезаурусного подхода, в том числе индикаторов «свое - чужое - чуждое».

Возражения у нас вызывает положение о парадоксе условной «равной ценности» «объектов», наполняющих тезаурусную сферу (см.: Ауков Вл., 2014: 311). Ссылки на особенности сферы как геометрического образования, точки которой равно удалены от ее центра, вряд ли помогут в обосновании этого положения. Вероятно, оно было выдвинуто, чтобы подчеркнуть важность внимания ко всем содержательным «объектам» сферы. В этой связи следует отметить одинаковое равноправие их со-существования, со-бытия в сфере, но никак не равную ценность. Компоненты сферы, будучи продуктами творчества различных субъектов с их тезаурусами, a priori не могут восприниматься, осмысливаться, оцениваться одинаково.

Не забудем также, что развитие сферы a priori предполагает подвижки, изменения в оценках содержательных компонентов. Сказывается и фактор культурноисторической дистанции: изменения в социокультурном состоянии, процессы и результаты приращения знаний, изменения в картинах мира, ценностях и нормах у тех или иных субъектов. Отдельные компоненты сферы могут затухать, забываться, смещаться на периферию или, наоборот, актуализироваться, привлекать повышенное внимание, порождать возвратные, обновленные и инвариантные интерпретации и репрезентации. И это происходит, подчеркнем, в рамках пространства тезаурусной сферы. О каком же парадоксе «равной ценности» можно говорить? Характерная особенность тезаурусной сферы в разной ценности ее содер- 
жательных компонентов для различных субъектов, «задействованных» в том или ином пространстве-времени и в том или ином качестве в формировании, функционировании, развитии этого виртуального образования.

Изменения в интерсубъектной тезаурусной сфере выступают важнейшим условием ее бытования. Поэтому исследовательский интерес должен быть направлен прежде всего не на раскрытие всего содержательного, зачастую многообразного наполнения конкретной сферы, а на выяснение характерных тенденций, общих особенностей, а также динамики и энергетики перемен, ее нелинейного развития, культурного влияния. Аополнительно отметим, что, когда речь идет о развитии сферы, следует принимать во внимание не только приращение знаний и не только особенности и проблематику конкретного социокультурного пространства (хотя эти факторы исключительно важны). Так, в рамках одной и той же социокультурной реальности мы сталкиваемся нередко с самыми разными, иногда противоположными, иногда и труднообъяснимыми интерпретациями, репрезентациями, рецепциями, «эффектами» разного рода, ведущими к изменениям в тезаурусной сфере вокруг исходного субъекта. Во всяком случае, не стоит забывать о субъективности субъекта, тем более индивида, о сложном сочетании проявлений его разума, воли и чувств, сознательного и бессознательного.

Содержательные компоненты интерсубъектной тезаурусной сферы всегда имеют отношение не только (иногда и не столько) к исходному тезаурусу, а и к тезаурусам и особенностям других социальных субъектов. Конечно, итальянский порнографический фильм по пьесе «Ромео и Ажульетта» (1998) отчасти питается шекспировским текстом, но, будучи провокативным, он несет преимущественную информацию не об этом гениальном произведении, не о новых значимых смыслах, а о тезаурусах и личностях его создателей, их ценностных ориентациях, сопрягающихся с расчетами на коммерческую выгоду. В сфере как специализированном образовании с большей или меньшей полнотой проявляется информация не только о тезаурусе исходного субъекта, но и о тезаурусах (если говорить об индивидах, то зачастую и о личностях) других субъектов.

И еще об одном. Тезаурусная сфера, хотя и порождена реальным социальным субъектом с его тезаурусом, может, в свою очередь, приводить к содержательным изменениям в самом тезаурусе этого исходного субъекта. Обоснованность такого посыла вряд ли будет оспариваться. В самом деле, каждый без труда сошлется на примеры подвижек или значимых изменений в тезаурусе субъекта, например, при жизни писателя, композитора, ученого, под воздействием других субъектов, за счет отклика на то или иное произведение или даже на проявления личной жизни. Под воздействием «внешнего фактора», в том числе особенностей рефлексий и репрезентаций, отражающихся в тезаурусной сфере, вполне могут происходить изменения собственно в исходном тезаурусе, как в зоне собственно «своего , так и в соотношениях «своего»- «чужого». Оговоримся, что такого рода содержательные изменения тезауруса допустимы при жизни самого социального индивида.

\section{ЗАКАЮЧЕНИЕ}

После смерти «жизнь» продолжается - мы говорим здесь о людях известных, - происходит пополнение тезаурусной сферы, причем нередко даже более значимое, чем при земной жизни. Но теперь уже речь идет не об изменениях 
в самом исходном тезаурусе, а об осмыслении и понимании этого тезауруса, его знаниевых компонентов, как и о понимании той или иной личности в актуальной памяти культуры.

\section{СПИСОК АИТЕРАТУРЫ}

Гуманитарное знание: тенденции развития в XXI веке. В честь 70-летия Игоря Михайловича Ильинского (2006) / под общ. ред. Вал. А. Аукова. М. : Изд-во Нац. ин-та бизнеса. $680 \mathrm{c}$.

Захаров, Н. В., Ауков, В. А., Ауков Вл. А. (2012) Шекспиросфера [Электронный ресурс] // Вестник Международной академии наук. Русская секция. № 2. C. 70-75. URL: http://www.heraldrsias.ru/online/2012/2/238/ (дата обращения: 11.06.2016).

Канарш, Г. Ю. (2015) Тезаурусный анализ и характерологическая креатология: два подхода в социально-гуманитарном знании // Мировая культура в русском тезаурусе: I Академические чтения памяти Владимира Андреевича Аукова, 27 марта 2015 г. : сб. науч. трудов / редкол.: В. А. Ауков (отв. ред.), Н. В. Захаров, Т. Ф. Кузнецова, Ч. К. Аамажаа, В. П. Трыков. М. : Изд-во Моск. гуманит. ун-та. 280 с. С. 126-134.

Иисович, И. И., Макаров, В. С. (2014) Научно-исследовательский проект «Виртуальная шекспиросфера: трансформации шекспировского мифа в современной культуре» // Знание. Понимание. Умение. № 2. С. 264-282.

Ауков, В. А., Захаров, Н. В., Ауков, Вл. А., Гайдин, Б. Н. (2012) Шекспиросфера (Шекспир, его современники, его эпоха в культуре повседневности) [Электронный ресурс] // Информационный гуманитарный портал «Знание. Понимание. Умение». № 3 (май июнь). URL: http://www.zpu-journal.ru/e-zpu/2012/3/Lukov Zakharov $\sim$ Lukov Gaydin Shakespeare-sphere/ (дата обращения: 11.06.2016).

Ауков, В. А., Ауков Вл. А. (2013) Тезаурусы II: Тезаурусный подход к пониманию человека и его мира. М. : ИзА-во Нац. ин-та бизнеса. 640 с.

Ауков, В. А., Ауков Вл. А. (2014) Шекспиросфера и культурные константы // Знание. Понимание. Умение. № 2. С. 200-208.

Ауков, В. А. (2015) Шекспиросфера как социокультурный конструкт: факт и воображение // Воображение и факт в конструировании художественных и виртуальных миров шекспировской Англии : сб. науч. ст. / отв. ред. и сост. И. И. Иисович. М. : Изд-во Моск. гуманит. ун-та. 176 с. С. 4-11.

Ауков, Вл. А. (2014) Концепция тезаурусных сфер // Знание. Понимание. Умение. № 1. C. 307-326.

Аата поступления: 15.06.2016 2.

\section{THESAURUS SPHERES: NEW APPROACHES \\ A.N. SVALOV \\ (Russian ACAdemy of Social SCIENCES, Moscow)}

Recently there has been an upsurge in interest in the thesaurus theory of knowledge which has been developed, in particular, by Val.A. Lukov and V1.A. Lukov. Research in thesauri done by scholars in various fields indeed leads to a better understanding of manifestations of human subjectness and subjectivity, and of how lifestyle and practice is informed by value orientations, which helps redefine existing theories and generate new ideas. One of such important innovations has been the concept of the thesaurus sphere. The article examines a number of conceptual ideas on the virtual image of this sphere.

We suggest that it should be analyzed apart from the thesaurus structure, as a specific entity centered on the original subject. At the same time, the metaphor of the sphere has no sense 
outside of the interaction of various social subjects, which allows us to define the thesaurus sphere as an inter-subject phenomenon of knowledge.

We believe that all components of the sphere are co-equal, but not of equal value. On the contrary, different subjects assign different value to various components of the thesaurus sphere.

We conclude by suggesting that changes in the sphere's structure and content are the most influential factor of its existence.

Keywords: social subject; virtual image; thesaurus approach; thesaurus; thesaurus sphere; methodology of the humanities

\section{REFERENCES}

Gumanitarnoe znanie: tendentsii razvitiia $v$ XXI veke. V chest'70-letiia Igoria Mikhailovicha Il' inskogo (2006), ed. Val. A. Lukov. Moscow, Nats. in-t biznesa Publ. 680 p. (In Russ.)

Zakharov, N. V., Lukov, V. A. and Lukov V1. A. (2012) Shekspirosfera. Vestnik Mezbdunarodnoi akademii nauk. Russkaia sektsiia, no 2, pp. 70-75 [online] Available at: http://www. heraldrsias.ru/online/2012/2/238/ (access date: 11.06.2016). (In Russ.)

Kanarsh, G. Yu. (2015) Tezaurusnyi analiz i kharakterologicheskaia kreatologiia: dva podkhoda v sotsial'no-gumanitarnom znanii. In: Mirovaia kul' tura v russkom tezauruse: I Akademicheskie chteniia pamiati Vladimira Andreevicha Lukova, 27 marta 2015 g. : sb. nauch. trudov, ed. V. A. Lukov. Moscow, Mosk. gumanit. un-t Publ. 280 p. Pp. 126-134. (In Russ.)

Lisovich, I. I. and Makarov, V. S. (2014) Nauchno-issledovatel'skii proekt «Virtual'naia shekspirosfera: transformatsii shekspirovskogo mifa v sovremennoi kul'ture». Znanie. Ponimanie. Umenie, no. 2, pp. 264-282. (In Russ.)

Lukov, V. A., Zakharov, N. V., Lukov, Vl. A. and Gaidin, B. N. (2012) Shekspirosfera (Shekspir, ego sovremenniki, ego epokha v kul'ture povsednevnosti). Informatsionnyi gumanitarnyi portal «Znanie. Ponimanie. Umenie», no. 3 (May - June) [online] Available at: http://www.zpu-journal.ru/e-zpu/2012/3/Lukov Zakharov Lukov Gaydin Shakespearesphere/ (access data: 11.06.2016). (In Russ.)

Lukov, V. A. and Lukov Vl. A. (2013) Tezaurusy II: Tezaurusnyi podkbod k ponimaniiu cheloveka i ego mira. Moscow, Nats. in-t biznesa Publ. 640 p. (In Russ.)

Lukov, V. A. and Lukov V1. A. (2014) Shekspirosfera i kul'turnye konstanty. Znanie. Ponimanie. Umenie, no. 2, pp. 200-208. (In Russ.)

Lukov, V. A. (2015) Shekspirosfera kak sotsiokul'turnyi konstrukt: fakt i voobrazhenie. In: Voobrazhenie i fakt $v$ konstruirovanii kbudozhestvennykb i virtual' nykb mirov shekspirovskoi Anglii : sb. nauch. st., comp., ed. I. I. Lisovich. Moscow, Mosk. gumanit. un-t Publ. 176 p. Pp. 4-11. (In Russ.)

Lukov, V1. A. (2014) Kontseptsiia tezaurusnykh sfer. Znanie. Ponimanie. Umenie, no. 1, pp. 307-326. (In Russ.)

Submission date: 15.06 .2016$.

Свалов Александр Николаевич - кандидат исторических наук, академик Российской академии социальных наук, г. Москва. Тел.: +7 (495) 399-15-83. Эл. адрес: ava-69@mail.ru

Svalov Aleksandr Nikolayevich, Candidate of History, Full Member, Russian Academy of Social Sciences, Moscow. Tel.: +7 (495) 399-15-83. E-mail: ava-69@mail.ru 